\title{
Diez propuestas para el estudio de las movilizaciones colectivas. De la experiencia al compromiso*
}

Daniel Cefaï**

\begin{abstract}
Resumen
El presente artículo revisa un cierto número de trabajos disponibles, tanto en Europa como en Estados Unidos, y propone dos desplazamientos en el análisis de las movilizaciones colectivas. En primer lugar, toma como hilo conductor la noción de experiencia heredada de la fenomenología y de la hermenéutica. Para entender lo que sucede en una movilización colectiva hay que investigar sobre los contextos de experiencia de los actores. En segundo lugar, más que centrarla en los movimientos sociales, aspirando al estatus de sujetos colectivos, la atención es desplazada hacia situaciones problemáticas. Intentando definirlas y controlarlas, diferentes actores se movilizan, entran en relaciones complejas de cooperación y de conflicto y configuran arenas públicas focalizadas en problemas públicos. El objetivo general del artículo no es invalidar los modelos existentes, sino más bien reorganizarlos y reagenciarlos bajo otra perspectiva.
\end{abstract}

Palabras claves: Movilizaciones - acción colectiva - experiencias sociales - redes.

\begin{abstract}
The present article reviews a number of works available, both in Europe and the United States, and proposes two shifts in the analysis of collective mobilizations. First, it takes as guiding principle the notion of inherited experience of the phenomenology and hermeneutics. To understand what happens in collective mobilizations it is necessary to investigate about actors' contexts of experience. Second, rather than focusing attention on social movements, aspiring to the status of collective subjects, attention is shifted to problematic situations. Trying to define and control them, different actors become mobilized, come into complex relationships of cooperation and conflict, and shape public arenas focused on public issues. The general objective of this article is not to invalidate existing models, but rather to reorganize them under a different perspective.
\end{abstract}

Keywords: Mobilizations - collective action - social experiences - nets.

* Traducción de Consuelo Biskupovic, Doctorante en Antropología, École de Hautes Études en Sciences SocialesUniversidad de Chile.

** Director de Estudios en la École de Hautes Études en Sciences Sociales, París, Francia. Correo electrónico: cefai@ehess.fr 


\section{PRESENTACIÓN ${ }^{1}$}

La sociología de las movilizaciones colectivas se ha convertido hoy en día en un campo de investigaciones plenamente constituido, que ha transformado nuestra manera de dar cuenta de la vida política. Este artículo pasa revista a un cierto número de trabajos disponibles, tanto en Europa como en Estados Unidos, y propone dos desplazamientos en el análisis de las movilizaciones colectivas. Primero, toma como hilo conductor la noción de experiencia -individual y colectiva, privada y pública- que heredamos de la fenomenología (Schütz, 1962-66) y de la hermenéutica (Koselleck, 1997). Más que partir de estructuras económicas, sociales o políticas preconstituidas, o postular un tipo de racionalidad estratégica a priori, para entender lo que sucede en una movilización colectiva hay que investigar ${ }^{2}$ sobre los contextos de experiencia de los actores. Una segunda operación es Ilevada a cabo en el transcurso de la investigación: más que centrarla en los movimientos sociales, aspirando al estatus de sujetos colectivos, la atención es desplazada hacia situaciones problemáticas. Intentando definirlas y controlarlas, diferentes actores se movilizan, entran en relaciones complejas de cooperación y de conflicto y configuran arenas públicas focalizadas en problemas públicos. Aquí, la referencia fundadora es el pragmatismo de John Dewey (1927). El objetivo general del artículo no es invalidar los modelos existentes, sino más bien reorganizarlos y reagenciarlos bajo otra perspectiva.

\section{EL CUESTIONAMIENTO A LA PRIMACÍA DE LA ACCIÓN RACIONAL}

Las investigaciones sobre movilizaciones colectivas son generalmente pensadas a partir de modelos de acción racional o de movilización de recursos. Despliegan un esquema explicativo que comienza con las condiciones objetivas (industria de los movimientos sociales, estructuras de oportunidad política), continúan con las estructuras de movilización (organizaciones y redes), y para terminar inyectan una dosis de representaciones colectivas (scripts o marcos). Estas representaciones colectivas son recibidas como un juego de limitaciones y de recursos discursivos, cognitivos y normativos, que viene a sumarse a otro tipo de limitaciones y de recursos, materiales y humanos. Los actores siguen objetivos que les parecen deseables, persiguiendo intereses que pueden ser pensados en términos de economía de bienes privados o públicos. Para lograrlo, deben sobrepasar su dispersión en individuos y encontrar puntos en común y reunirse en torno a ellos -lo que puede dar lugar a toda suerte de dilemas, siendo uno de los más famosos el del prisionero (Olson)-. Con este fin, movilizan toda suerte de "recursos", disponibles en las instituciones o incorporados por humanos, e intentan, según un principio de racionalidad, maximizar la eficacia de la relación medios-fines y el rendimiento de la relación inversiones-ganancias. Crean estas

1 Este texto fue presentado por primera vez en la Universidad de Chile, en Santiago, gracias a la invitación de Emmanuelle Barozet, ayudada por Consuelo Biskupovic y Eduardo Canteros. Les doy las gracias, así como también a los evaluadores anónimos por sus observaciones.

2 Tomamos aquí la noción de "investigación" (inquiry) en un sentido genérico. Claramente privilegiamos los métodos cualitativos (microhistoria, etnografía o biografía), pero sin excluir a priori el análisis de redes o la modelización de contexto. 
máquinas de combate que son las asociaciones, sindicatos o partidos, que modifican las relaciones de fuerza, las distribuciones de recursos y las reparticiones de poderes. Entablan alianzas con otros portadores de causas o buscan apoyos en el campo de sus adversarios. Juntan dinero, armas o tropas, se esfuerzan en agregar competencias como las de los clérigos religiosos, abogados o científicos y sumar a los miembros ricos en términos de poder o de prestigio. De esta manera, se someten a limitaciones estructurales de orden económico, político, institucional... que se les imponen, remodelando el entorno en que se encuentran.

En estricto sentido, la figura del homo oeconomicus puede ser complejizada si equipamos a los agentes, como lo hizo Bourdieu (1980), con capitales económicos, sociales, culturales, políticos o comunicacionales, y si retomamos sus intereses bajo una perspectiva social e histórica. Estos son determinados por una posición y una trayectoria en el campo social y son dotados de agenciamientos y de recursos que pueden ser específicos a un subcampo de la vida social. El campo de los compromisos es a la vez posible y limitado por la posesión de un "capital militante" (Matonti y Poupeau, 2004). En algunos mundos sociales, los intereses deben ser ampliados para incluir, además de los intereses materiales, el interés por preservar y reproducir el orden normativo que guía la legitimidad de las acciones: los actores obedecen a lo que les es dictado por la religión, el derecho o por la moral y pueden rebelarse cuando ciertas situaciones contradicen sus valores. Pueden luchar por el advenimiento del Reino de Dios en la Tierra, contra el desmantelamiento del Estado de bienestar, por el reconocimiento de los derechos de autonomía de los pueblos indígenas o, simplemente, porque la "economía moral" (Thompson, 1971) que regulaba las relaciones de explotación o de dominación ya no es respetada. Todo el problema es saber hasta qué punto este prolongamiento de la perspectiva de la teoría de la elección racional y la redefinición de las categorías de "recurso", "capital", "mercado", "inversión", "estrategia", "limitación", "oportunidad" pueden hacerse en el marco de una "economía general de las prácticas", que integre una "economía de los bienes simbólicos".

Es contra esta hipertrofia del discurso económico que se ha desarrollado en Francia una sociología del juicio estético, moral y político. Lo que estaba en juego era ser nuevamente sensible a los compromisos del deber, de responsabilidad o solidaridad frente a los cuidados de sí $^{3}$ y del otro o a los ideales del "buen vivir-juntos" que están en juego en las acciones colectivas (Queré, 2002). El estudio de la razón práctica fue entonces transferido desde la filosofía a las ciencias sociales. El programa de investigación que tuvo más repercusión en Francia fue el de L. Boltanski y L. Thévenot (1991) sobre la "justificación en público". No hay un solo tipo de racionalidad ni un solo tipo de legitimidad en juego en una movilización colectiva, sino que una multiplicidad de regímenes de compromiso y de justificación que se combinan unos con otros. Los autores proponen una tipología de "ciudades"4 que complejizan

3 N. del T.: Referencia a la idea de Souci de soi del tomo 3 de la Historia de la Sexualidad, de M. Foucault, para hablar de cómo las movilizaciones colectivas conducen a nuevas percepciones y apreciación de sí y a un trabajo de y sobre sí.

4 N. del T.: Siguiendo a los traductores de El nuevo espíritu del capitalismo (Akal, Madrid, 2002) hemos traducido el término cités de la obra de Boltanski y Chiapello como "ciudades". Este término proviene del latín civitas, civitatis. 
la investigación y el análisis: junto a la ciudad mercantil, distinguen la ciudad industrial (compromiso ingenieril que racionaliza la relación medios-fines), cívica (compromiso republicano en el nombre del bien público), doméstica (compromiso entre familiares que pasa por la relación interpersonal), de opinión (compromiso guiado por el crédito acordado por la mayoría) y de la inspiración (compromiso de tipo carismático, estético o místico). Más radicalmente, A. Pizzorno (1986) y Melucci (1996: 66) han mostrado que el cálculo racional como tal es imposible si no se inscribe en un marco de referencia que escape al cálculo. Lo primero es la necesidad, que es no-racional, de dar sentido al vivir-juntos, lo que se traduce en objetivos afectivos, identitarios y simbólicos, a través de los cuales nos constituimos como un sí mismo y organizamos nuestra vida colectiva.

Este desplazamiento tiene varias consecuencias: i) los contextos de experiencia de los actores son entonces el punto de partida de la investigación. Ésta debe ante todo apoyarse en las categorías que organizan la experiencia de los actores, y a las que pueden dar sentidos extremadamente diversos según la situación en que se encuentren. Los contextos de experiencia no son reductibles mediante razonamientos estructurales o económicos: deben ser descritos y comprendidos en sí mismos, y es desde ahí que deben emerger tentativas de explicación y de interpretación. Esto no invalida los procedimientos más formales, pero requiere siempre reanclarlos y preguntarse: ¿qué es una limitación económica, una oportunidad política, una red social, una estrategia identitaria, una dinámica cultural o un dilema moral, desde el punto de vista de un actor particular? ¿Qué consideran racional o razonable en una situación dada?. ii) Esto implica entonces recurrir a métodos de investigación cualitativa, si es posible microhistórica, biográfica o etnográfica, con el fin de delimitar los contextos de experiencia de los actores -sus elecciones racionales, evidentemente, pero también sus conflictos de lealtades, sus apreciaciones estéticas, sus dudas éticas o sus preferencias políticas-. Más vale comenzar por intentar comprender cuál es la situación problemática a la que las personas están confrontadas y qué las lleva en un momento dado a comprometerse en una acción colectiva, en vez de probar con modelos preestablecidos. iii) Finalmente, un último elemento que caracteriza esta corriente en ciencias sociales es que ya no deifica los macroprocesos o las macroestructuras (las "clases sociales", las "organizaciones revolucionarias", el "Estado", la "sociedad civil"...). Se esfuerza, cada vez que puede, por mostrar procesos de coordinación, de interacción o de comunicación. Trata de comprender cómo, en contextos de experiencia de los actores, estos se encargan de tales entidades, u otras, y cómo son tomadas en cuenta, restituyendo la manera en que los actores se transforman en "actores", y cómo crean "organizaciones" y hacen "política".

\section{III. ¿EXISTEN LOS MOVIMIENTOS SOCIALES?}

La categoría de "movimiento social", por ejemplo, debe ser manipulada con mucha circunspección. A veces, el bosque no nos deja ver los árboles. La primera operación que debe ser llevada a cabo sería la de descomponer la categoría de "colectivos" que "se" movilizan. No dar más por sentada su existencia en tanto que persona colectiva. Esto no es nuevo, porque esta crítica de la ontología, que imponía desubstancializar los colectivos, remonta a Weber, y la reencontramos en Schütz, Popper o Hayek, entre otros. Aquí no se 
trata exactamente de lo mismo, porque el problema no es luchar contra una especie de organicismo o de holismo que niega la existencia de los colectivos en nombre de los valores del individuo. El problema es más bien preguntarse cómo son hechos los "colectivos", de qué y por qué, y mediando qué operaciones. "Movimiento social", ¿qué quiere decir?

La investigación trata entonces primero sobre las actividades de categorización de los "colectivos" (Kaufmann y Trom, 2010). Estos sólo existen si los nombramos, los individualizamos y los identificamos, antes de simbolizarlos y representarlos. Un colectivo es antes que nada el uso de un nombre, de pronombres personales -Nosotros, Ustedes, Ellos- y de adjetivos posesivos -nuestra historia y nuestra lengua, sus derechos y su violencia-, en todo caso deícticos que le dan un lugar gramatical en las frases y que le otorgan un lugar en los juegos de interacciones. Un lugar de sujeto activo o pasivo: "La 'red' sufrió mucho con esta situación" o "La 'asociación' se compromete en favor de esta causa". Sujeto al que le atribuimos vicios y virtudes: "Esta 'organización' mostró que era peligrosa para la democracia" o "El 'Partido' es la carne y la sangre del Pueblo". Esta persona está provista de consciencia, de intenciones y de perspectivas, de intereses y de opiniones, endosadas por sus miembros que hablan como un "Nosotros": "nuestro punto de vista es...", "nosotros tomamos la decisión de...". Puede además tomar diferentes caras en diferentes lenguas e historias: el Nosotros de "Nosotros el Pueblo" en Francia es pensado como un corpus, mientras que el We de "We the people" en Estados Unidos es plural. Y esta persona, comúnmente, no existe plenamente como persona colectiva, habilitada para hacer uso del derecho de responsabilidad, siendo entonces susceptible de ser juzgada, condenada y disuelta, salvo si se instituyó por actos rituales de fundación, fue sancionada por actos jurídicos de inscripción y/o representada por actos políticos de transubstanciación. El movimiento social se representa como tal en el triple sentido cognitivo, teatral y político.

El caso de los "movimientos sociales" es aún más complicado. La "doble hermenéutica" cobra más sentido que nunca: la categoría erudita se transformó en lenguaje común, y la categoría ordinaria fue retomada por el discurso erudito. Lejana heredera de la soziale Bewegung, que acoplaba movimiento obrero y cuestión social, la noción de "movimiento social" fue retomada por una generación de activistas en los años sesenta-setenta, para nombrar el florecimiento de actividades reivindicativas de la época; y se convirtió en un "marcador identitario" para una comunidad de investigadores, especialmente en Europa en torno a Touraine, Melucci u Offe. Esta noción se debilitó en los años ochenta, para resurgir con fuerza en Francia a partir de mediados de los años noventa con el renacer de las luchas de trabajadores contra la nueva situación económica, y la constitución de un "movimiento" altermundialista y de movimientos de los "sin" (papeles, trabajo, casa). Estos últimos retomaron la etiqueta de Nuevos Movimientos Sociales (NMS) para designar sus "nuevas" formas de "política contestataria". Sin embargo, el término perdió una buena parte de su sentido inicial. Ya no apuntaba al horizonte de sobrepasar la historia o al de la emancipación de la humanidad. Ni aparecía investido por la misión de la clase obrera de hacer la revolución, aunque algunos movimientos soñaran con acabar con el capitalismo y el liberalismo.

Este uso de la categoría de "movimientos sociales" es reemplazado en parte por las ciencias sociales y políticas. ¿Pero cómo pasar del léxico vernáculo a una categoría descriptiva y 
analítica? ¿Y cómo tomar en cuenta las transformaciones que estos conocieron, reciclando por ejemplo la etiqueta de NMS? ¿Su alcance utópico y la tensión normativa que los habitaba no han sido acaso alterados? ¿Estos "movimientos" se piensan a sí mismos como "movimientos" y se comprometen en los procesos de unificación y de identificación, de designación de adversarios y de definición de conflictos que supuestamente los caracterizan? ¿O acaso no se trata, la mayoría de las veces, de movilizaciones locales, parciales, fragmentadas, divididas, con serios problemas para coordinarse entre ellas, en general concentradas en un solo problema, sin visión de conjunto? ¿No son estos "movimientos", en gran medida, dependientes de iniciativas políticas y administrativas o de las transformaciones del mercado económico -a menos de que no participen en dispositivos de gobernanza urbana o política-? ¿Y tiene sentido juntar la multiplicidad de escozores del cuerpo social bajo la etiqueta de "movimiento" -aun si este se da en una plataforma de coordinación y una escena de visibilidad con foros sociales mundiales-?

Esta serie de interrogantes no impide hacer de "movimiento social" una categoría descriptiva y analítica, pero a condición, primero, de identificar las ocurrencias y de tomar las significaciones en tanto que categoría práctica que organiza la experiencia de los actores. Segundo, no ceder a la ilusión de su unidad y de su identidad, sino que mostrar cómo se hace, concretamente -cómo se organiza, se unifica y se identifica en situaciones problemáticas por resolverse-.

\section{ORGANIZACIÓN... LOS CONFLICTOS, LAS ESTRATEGIAS Y LAS SOCIABILIDADES}

Hemos visto que las palabras deben ser utilizadas con precaución, adivinando las ambivalencias de la relación del investigador con su "objeto". Investigar, describir y analizar, es practicar cierto "estrabismo metodológico". Por un lado, el investigador toma en serio lo que dicen los actores, porque sus maneras de ver, de decir y de hacer organizan las experiencias, individuales y colectivas. Los "colectivos", para existir públicamente, deben ponerse en escena, en argumento y en relato, y el investigador se adentra en configuraciones de sentido para comprender, antes de contar, de explicar y de interpretar. Considera un campo de creencias participando en él. Por otro lado, al mismo tiempo que le da voz a sus encuestados $^{5}$, el investigador no puede tomar el lugar de portavoz de los actores: debe activar su capacidad de duda, examinar lo que dicen y no hacen, y lo que hacen y no dicen, lo que hacen diciendo algo y lo que dicen cuando hacen algo. No debe en ningún caso acreditar las empresas de justificación y de idealización y debe extirparse del campo de creencias para dar cuenta de éste -actuar como un sabio y no como un político, sabiendo que sigue siendo, irremediablemente, un "espectador comprometido"-. Por ejemplo, no debe ceder a la tentación de retomar sin distancia la etiqueta de "movimientos sociales", y buscar identificarlos, unificarlos y concientizarlos -aun cuando en esas operaciones de investigación

$5 \quad$ N. del T.: Traducción de enquête, que en la tradición de las ciencias sociales en Francia hace referencia a la persona que el investigador entrevista, observa, con quien entabla relación, etc. Es decir, una noción mucho más compleja que la de "encuestado" en el sentido propio de quien responde una serie de "preguntas tipificadas (...) para averiguar estados de opinión" (RAE). 
debe participar en las acciones-. Pero debe, al mismo tiempo, tomar esta etiqueta como un tema de investigación, preguntarse por lo que hacen y no hacen los actores poniéndola en juego -cuál es la performatividad de su uso- y dar cuenta de las actividades prácticas que se configuran ante el desafío de organizar la experiencia pública de la protesta.

Esta dificultad se encuentra al tratar de estudiar las organizaciones. En la versión estándar que se impuso a partir de los años sesenta-setenta, en un momento clave de invención de un nuevo tipo de ONG por Ralph Nader, seguido rápidamente por una tendencia masiva a la racionalización y a la gestión de las organizaciones, las OMS fueron tratadas como empresas que movilizan recursos materiales y simbólicos en contextos en los que están en competición con otras empresas, en vista de lograr objetivos siguiendo estrategias lo más eficaces y rentables posibles. Este posicionamiento fue importante: rompió con visiones menos articuladas de la organización que precedían en las sociologías del collective behavior, y dio las claves de lectura de un nuevo tipo de organización que se establecía en ese momento. Pero mantuvo la visión de una industria o de un mercado de los movimientos sociales (Zald y McCarthy, 1977), promovidos y dirigidos por empresarios, en competición unos con otros tanto para definir los problemas sociales y lograr cambiar la jerarquía de las prioridades en las agendas mediáticas, políticas o administrativas, sólo para captar auditorios y clientes, sensibilizarlos, concernirlos y movilizarlos, y ganar, acumular e invertir recursos de acción. Este posicionamiento tenía una pertinencia descriptiva y explicativa, en la medida en que se ajustaba con los modos de organización de la experiencia de numerosos activistas norteamericanos a los que aludía. Pero fue exportado sin que su universalidad fuera interrogada y sin precaución de traducción.

Esta visión muy empresarial, reanclada en una sociología histórica y un análisis de redes en la perspectiva de la movilización de recursos de Oberschall (1973), prevalece aún, por muy enmendada que esté. Resulta aún más creíble en la medida en que las organizaciones se constituyen en contextos donde prevalecen prácticas de gestión o de estrategia, de administración y de evaluación copiadas de las empresariales. En Francia, "la economía general de las prácticas" de Bourdieu (1980) se posicionó contra esta perspectiva, aunque retomando ciertos elementos. Bourdieu combinó un análisis en términos de producciónconsumo y un análisis en términos de fuerza-dominación. La capacidad de los agentes sociales de comprometerse es aquí directamente indexada según la posesión de distintos tipos de capitales, diversamente distribuidos, y sólo entonces según su posición y trayectoria en el campo social. Las organizaciones parecen instrumentos de la acción colectiva, formados por representantes que se autoproclaman portavoces $y$, siguiendo sus propios intereses, permiten a los más desposeídos, privados de medios y de voz, llevar a cabo los suyos en las luchas materiales y simbólicas. Bourdieu lee esto de dos maneras. Diferentes fracciones de la "clase dominante" poseen un cuasimonopolio de la producción de las políticas públicas y de la representación política y mediática, ofrecidas a consumidores pasivos y alienados (Bourdieu, 1979). Esta relación de oferta y demanda es una relación de fuerzas, material y simbólica, mediante la cual "dominantes" ejercen su poder sobre "dominados": el funcionamiento de las organizaciones representativas está fundado en el ejercicio de una violencia simbólica. Bourdieu recicló así la metáfora del mercado en 
una sociología crítica, que dio lugar en Francia a una sociohistoria de grupos de interés y de los mercados políticos.

Sin embargo, ¿podemos contentarnos con tratar a las organizaciones como empresas, y a sus líderes como empresarios? Mientras más organizada esté la arena pública como un mercado, más sentido tiene esta tesis: los actores mismos se proyectan en la acción mediando cálculos de tipo instrumental y estratégico y realizan transacciones y negociaciones de interés. Pero esta retórica económica tiene también sus límites. Insiste en una dimensión y olvida todas las otras. Si los conflictos de interés y las relaciones de fuerza tienen un lugar innegable en los asuntos humanos, ¿implica esto acaso que sólo podamos analizarlos bajo este ángulo? ¿Qué pasa con el deseo de verdad, el sentido del derecho, el Ilamado a la justicia o el amor por la libertad? Cuando se despliega un nuevo problema público, ¿lo hemos circunscrito bien al preguntarnos "a quién beneficia esto"? El interés, en estricto sentido, ¿es acaso el único motor de la humanidad, y esta noción no debe ser acaso totalmente repensada? Si observamos las organizaciones más de cerca, vemos aparecer un paisaje mucho más complicado, donde se entrechocan y se recortan racionalidades y legitimidades "híbridas" o "heterogéneas" (Thévenot, 2006; Eliasoph, 2011). Los modos de producción de conocimientos, de toma de decisión, de ejercicio del juicio y de resolución de los problemas son variables según las situaciones. Las fórmulas de coordinación entre personas y cosas, los compromisos encontrados en torno a convenciones comunes, los arreglos tácitos y prácticas en la acción común, las maneras de situarse en un contexto y el hacer de esto el lugar de la acción colectiva, son de una gran diversidad. Cada organización inventa un contrapeso entre muchas experiencias de racionalidad y de legitimidad, en transacciones que privilegian una u otra, y que suscitan batallas y discusiones, renuncias o partidas. Más que rebajar todo a una perspectiva económica, más vale rastrear las tensiones que se muestran entre estas formas plurales de compromiso.

Aunque el grado de institucionalización, de formalización y de codificación de las actividades y de las relaciones en las organizaciones es alto, éstas conservan el carácter de arenas intraorganizacionales. Resultan de una actividad coordinada entre segmentos étnicos o profesionales, entre instancias locales y regionales, entre niveles estratégicos y tácticos. Ponen en práctica una división del trabajo, una repartición de poderes, de derechos y de prerrogativas entre dirección, marcos y miembros. Son divididas en plazos temporales (cortos y largos) y en escalas territoriales de geometría variable. Deben fijar jerarquías de urgencias y de prioridades, combinar los "medios escasos de usos alternativos", regular las tensiones y los litigios internamente y darse una línea más o menos coherente. Aunque su apertura en redes y su permeabilidad hacia flujos son hoy en día consideradas, tienen cada una su propio "estilo organizacional": mantienen un cierto tipo de fronteras con el mundo exterior (boundaries), lazos con otros miembros (bonds) y normas discursivas (speech norms) que hacen reconocible el ambiente y el ethos que reinan en ellas. Además, ocupan lugares en las arenas interorganizacionales, donde entran en competencia unas con otras. Y no sólo para concentrar la mayoría de los recursos, de poder material y de crédito simbólico: si una parte de las estrategias organizacionales es atribuible a la autorreproducción y autorreforzamiento, no son solamente vectores de concentración de capitales. También organizan la experiencia 
y fabrican vínculos (De Leonardis, 1990). Son generadores de energía utópica, difunden nuevas ideas y creencias, permiten reconocer identidades y hacen valer derechos, luchan por objetivos de paz, de libertad o de justicia... Las arenas interorganizacionales pueden ser calificadas de públicas en la medida en que, más allá de los problemas de fuerza y de interés, se dibujan procesos de configuración de problemas, están orientadas por una preocupación del bien público, por disputado que sea, y apuntan a una inscripción de soluciones propuestas en un marco institucional, sancionado por instituciones políticas (estatales o internacionales).

\section{DEL POLITICAL PROCESS A LA CONTENTIOUS POLITICS: LA EXPERIENCIA DEMOCRÁTICA}

Por más que dejemos afuera lo político, este siempre reaparecerá. La existencia de movilizaciones colectivas es indisociable de la aventura democrática y esta dimensión fue establecida por los análisis de los procesos políticos - desde las revueltas contra el impuesto de los campesinos en el siglo XVII, descritas por Tilly, hasta el Movimiento de los Derechos Cívicos que describe McAdam en el siglo XX-. Pero por mucho tiempo el análisis ha sido concebido exclusivamente como una lucha frontal entre establishment y challengers o outsiders. Limitaciones y oportunidades políticas dependían de la disposición frente a la apertura o el cierre del sistema político: propensión del Estado para negociar o reprimir en caso de conflicto, grado de centralización y concentración de la administración pública, fuerza o fragilidad de las alianzas entre élites económicas, sociales y políticas, existencia de mecanismos de participación y de representación de intereses de los dominados. Esta determinación mecánica de las movilizaciones colectivas por estructuras de limitación y de oportunidad política desde entonces se ha complejizado, con una reelaboración del modelo del political process en un modelo de contentious politics (McAdam et al., 2003; Tarrow y Tilly, 2007).

En efecto, hoy en día todo tipo de conflictos es tomado en cuenta, inclusive los conflictos revolucionarios o sindicales, hasta hace poco excluidos de la literatura sobre movimientos sociales. La investigación se ha desviado hacia dinámicas de incorporación, de transformación y democratización del Estado, reuniendo así problemáticas de participación política. Giugni (1998) propone por ejemplo la tripartición siguiente. Incorporación: las movilizaciones colectivas pueden dar lugar a la fundación de asociaciones, de partidos o de sindicatos que integran el edificio institucional. Sus reivindicaciones pueden todavía ser traducidas en el corpus de leyes votadas en el parlamento, en las agendas de políticas públicas o en los programas de partidos políticos. Transformación: el sistema político conoce una modificación de las reglas de juego y una redistribución de los poderes institucionales -por ejemplo, estableciendo el escrutinio electoral proporcional, abriendo más puntos de acceso a la vox populi por la mediación de mecanismos de consultación o la intercesión de cuerpos intermediarios-. Democratización: una etapa siguiente es alcanzada cuando los derechos y los deberes mutuos entre el Estado y los ciudadanos son redefinidos y cuando nuevos derechos, recursos y prerrogativas son adquiridos por los ciudadanos. Puede tratarse de políticas de redistribución de recursos, en el nombre de la igualdad de oportunidades -acción afirmativa o discriminación positiva por ejemplo-, creación de jardines infantiles 
en respuesta a las demandas de las feministas o movilización de presupuestos en vista de favorecer el desarrollo urbano. Puede tratarse de políticas de reconocimiento que garanticen una protección de las minorías contra el arbitraje social o estatal, dando un estatuto particular a ciertos grupos nacionales, étnicos o religiosos y promoviendo el derecho a enseñar sus lenguas en el colegio o de utilizarlas en la administración.

En todos los casos, la concepción del "sistema político" es alterada por la consideración de las movilizaciones colectivas. Esta tipología podría fácilmente ser enriquecida por una cartografía de modos de interacción concretos entre Estado, sociedad política y sociedad civil, que explore sus zonas de interfase, sus espacios de interpenetración, sus lugares de mediación y sus puntos de fricción. Más finamente, habría que mostrar, según las situaciones, según las fases de su despliegue y según las etapas de su institucionalización, cuáles son los lugares asignados a los diferentes actores en los conflictos. Así, el Estado no es ya sólo un adversario, sino que las diferentes instituciones estatales pueden ocupar el lugar de enemigo o de aliado, de investigador, de legislador o de juez, de mediador o de justiciero; y la lucha abierta puede combinarse con procedimientos accesibles al núcleo del Estado: órganos de consultación, consejos de conciliación, referéndums populares, comisiones de investigación, jurados deliberativos, representación en proyectos de planificación... Recurrentemente, este tipo de institucionalización de la participación política es en sí mismo el resultado de movilizaciones colectivas y responde a reivindicaciones del derecho a tomar partido en los asuntos públicos. A cambio, la institucionalización transforma la situación: sin duda, da acceso a las esferas del poder, pero otorgando más o menos prerrogativas, en general dando la palabra, pero reservándose el poder de decisión. Sin duda, abre nuevos espacios de voz colectiva y pública, pero frecuentemente manteniendo el control sobre la agenda, sobre el repertorio de temas y la gama de preguntas. Y, acreditando a ciertos actores, alzados a la representatividad política, desacredita a otros, dejándolos en la banca; designa los interlocutores autorizados y les otorga un poder de mediación, a veces sostenido por la canalización de recursos específicos. Remodela entonces el espacio de la protestación colectiva, calmando a unos y agitando a otros, dándose interlocutores oficiales, al mismo tiempo que priva de voz a sus competidores, asegurándose gracias a redistribuciones diversas del consentimiento de la mayoría y gestionando el espacio público mientras mantienen el control tanto como pueden.

Algunas movilizaciones colectivas imprimen entonces sus marcas en programas de políticas públicas y en los dispositivos de representación política -manteniéndose en parte fuera del juego institucional-. Otras logran capitalizar sus experiencias, la reputación y confianza que han ganado, sus redes, sus saberes y sus recursos, institucionalizándose en organizaciones del mundo asociativo, sindical o partidista. El proceso político, tanto en esta capacidad para conquistar lugares en el sistema político y ejercer una influencia sobre los poderes instituidos, como en la capacidad de enunciar nuevos deseos y necesidades, hace valer nuevos intereses y escuchar nuevas opiniones, y hace emerger nuevos problemas públicos. Las movilizaciones colectivas convocan nuevos actores, visibles y audibles en el espacio público -los "movimientos de los sin" (trabajo, casa, papeles) aseguran por ejemplo la representación de grupos desprovistos de poder (Mouchard, 2009)-. Alteran las formas 
de la experiencia pública y crean focos de poder en contraste con los poderes políticos, económicos o administrativos. Y hacen avanzar la causa del derecho (Sarat y Scheingold, 2006; Israël, 2009). Pero la ecuación fácil entre movilizaciones colectivas y política democrática debe ser puesta en cuestión. Frecuentemente, los investigadores hacen suyas las posiciones de los actores y siguiendo sus convencimientos ciudadanos, asumen la división entre movimientos "progresistas" y "reaccionarios". Idealizan a veces ciertos "movimientos", adhieren sin distancia a sus reivindicaciones públicas y las trasladan a sus análisis -quedando ciegos a toda suerte de lugares de investigación-. O entonces, toman el camino contrario y deploran la falta de democracia, la corrupción o el clientelismo, el paternalismo o el caudillismo de sus organizaciones. El problema en el trabajo de investigación y de análisis es describir sin complacencia e interpretar sin posicionamientos -y más allá de la honestidad deontológica, auto-analizar sus propias creencias, tendencias y preferencias para ganar una mayor reflexividad respecto a su tema de estudio-. Y dar cuenta de la complejidad y del carácter a menudo ambiguo o paradójico de los procesos políticos, donde se imbrican movilizaciones colectivas y políticas públicas, representativas, negociaciones de interés y conflictos de poder.

\section{REDES Y PROTESTA: LOS APORTES DEL ANÁLISIS DE REDES}

El análisis de redes ha hecho grandes avances técnicos a partir de los años cincuenta. Poco a poco ha perfeccionado sus instrumentos de medida y de cartografía y diversificó sus puntos de vista. Hoy en día, disponemos de una amplia gama de métodos. El análisis estructural, el más objetivante, permite visualizar grados de segmentación o entrelazamiento, de centralización o de dispersión entre redes de personas o de organizaciones. Permite localizar huecos estructurales y dar cuenta de relaciones de mediación, de coordinación o de representación. Identifica coaliciones entre élites económicas y políticas, y permite recruzar redes de intercambio, poder y notoriedad. Puede analizar la elección del conformismo o la difusión de las innovaciones como propiedades emergentes. El análisis de redes puede igualmente aplicarse al estudio de pertenencias de los individuos a medios o a círculos múltiples. Puede ligar el multiposicionamiento de individuos a fenómenos de cumulación de poderes o de circulación entre organizaciones -frecuentemente los leaders son brokers (Diani y McAdam, 2003)-. De la misma manera, da cuenta, y contrariamente al optimismo de los discursos sobre el capital social, de los mecanismos sobre el clientelismo político y las relaciones orgánicas que ligan movimientos y élites (Knoke, 1990). Permite una comprensión fina de los anclajes socioprofesionales, económicos o territoriales, y a partir de esto permite inferir el intercambio de perspectivas o la formación de lazos de confianza en las movilizaciones colectivas. Puede, finalmente, cartografiar las relaciones de afinidad o de sociabilidad de una persona, y conectarlas con dinámicas de compromiso en las movilizaciones colectivas. Hoy en día, las redes ya no son solamente consideradas como una especie de estructura social: se muestra cómo fijan un contexto de decisiones, experiencias e identidades individuales. "Las redes sociales son realidades fenomenológicas" (Passy, 2005). Ofrecen oportunidades de reencuentro, amistad y discusión, de cooperación y competición. Crean medios de sociabilidad y socialización, y fabricando lazos personales a través del 
juego del interconocimiento y del reconocimiento, aseguran el compartir una comprensión de situaciones sociales. Fundan una experiencia colectiva en un mundo común.

Estas investigaciones ya han producido numerosos resultados empíricos (Diani y McAdam, 2003). McAdam (1988) aplicó este método al Freedom Summer del Movimiento de los Derechos Cívicos. También fue tomado en cuenta el movimiento creciente de proliferación de iglesias, clubes y círculos, de brotes de movimientos sociales y de asociaciones profesionales, la extensión, diversificación y densificación de conexiones sociales que caracterizan las "transiciones democráticas". En los años ochenta, las organizaciones de oposición se multiplicaron y aumentaron en efectivos en los países del este: desarrollaron redes de lazos aún más numerosos y múltiples entre organizaciones. De esta manera, Osa (2001) analizó en Polonia las olas sucesivas de revitalización de la sociedad civil, correlativas a la apertura de microespacios en un contexto autoritario, que llevaron a la revolución de Solidarnosc. Los grupos de rock, el sindicato estudiante NZS y los institutos universitarios se convirtieron en espacios de resistencia de la juventud, desarrollando luego de las huelgas de mayo y junio de 1988 una alianza con los obreros del Partido Obrero Unificado. Dinámicas similares han sido descritas en otros países de Europa del Este o de América del Sur. En Partisan Publics Mische (2008) reconstituye el movimiento para el impeachment del Presidente de Brasil, Collor de Mello, en 1992, cruzando datos de terreno y un análisis de redes de organizaciones. Muestra la multiplicidad de componentes de la protesta social y política, y describe el ejercicio de la convergencia de sus convicciones y de sus opiniones para que una coalición, que no durará mucho una vez alcanzado el objetivo, sea posible. Intenta introducir una variable temporal mostrando cómo los eventos - declaraciones de miembros del gobierno o de la oposición, escándalos de corrupción revelados por los medios de comunicación, momentos fuertes de meeting o de manifestación- son catalizadores de indignación o de esperanza y conducen a reagenciamientos de los frentes de alianzas. Le da a las redes la carne de la experiencia pública.

En fin, ha emergido un conjunto de trabajos extremadamente interesantes que ponen en cuestión las tipologías estrictas de los OMS, asociaciones voluntarias, sindicatos y partidos políticos e, incluso, las de los grupos de presión. Diani (1992) fue el defensor de una visión de los movimientos sociales en tanto que redes, reivindicando una referencia al concepto de catnet de Tilly (1978), al de identidad colectiva de Pizzorno (1986) y sobre todo al de las redes sumergidas de Melucci (1996). Más que dividir estos diferentes tipos de organizaciones, propone recruzar las áreas de estudio en cuestión. Más que hablar de "contrapoder" o de "comunidad cívica", el análisis de redes muestra claramente esquemas de transacción entre organizaciones más o menos formales o informales, más o menos isomorfos a aquellos en vigor en el Estado o en el mercado, más o menos centralizados o policentrados, más o menos integrados o segmentados. Estos clusters de organizaciones pueden estar orientados hacia la creación de lazos de sociabilidad o de solidaridad, hacia la producción de servicios propios del tercer sector, hacia la promoción de nuevas formas de experiencia de relaciones de género, de pluralismo cultural o de la ecología o hacia relaciones de conflicto con instancias de poder político en relación con los "sin papeles" o de poder económico frente a los despidos. Algunas de estas organizaciones son parte activa 
en las configuraciones de política institucional, por ejemplo, de operadores en las redes de acción pública -defensa de derechos de minorías o acción sanitaria y social-. Otros, conservando un espíritu activista, parecen cuasiempresas que rivalizan en el mercado de bienes y servicios, ya sean medios alternativos, turismo durable o software. En este caso más que en otros, la sociología de los movimientos sociales coincide con la de las organizaciones comunitarias, de la economía social o de la economía solidaria. Y, a veces, con la de partidos políticos: estos encuentran una base en los movimientos populares y asociaciones urbanas, donde contratan ejecutivos aguerridos y legítimos, se apropian de las redes de miembros y beneficiarios transformándolos en militantes y en clientes. Los ejecutivos que agitan el llamado al voto y a las manifestaciones, distribuyen dinero, bienes y servicios recalificando la ayuda social en ayuda política, orientando los fondos de las ONG internacionales para fines partisanos, instrumentalizando los programas de ayuda alimentaria, para la salud y el hábitat, y convirtiéndose en futuros candidatos a las elecciones. Los movimientos sociales constituyen entonces una base, una mina de confianza, de recursos y de competencias para los partidos políticos (Sawicki, 1997) -a menos que no se transformen, en algunos casos, en competidores de estos-.

\section{INTELIGENCIA ORGANIZADA Y AGENCIAMIENTOS SOCIOTÉCNICOS}

Este concepto de redes reenvía también al análisis de nuevas técnicas de información y de comunicación. La vida de las redes de las organizaciones y de las instituciones está ligada a las potencialidades de sus agenciamientos sociotécnicos. La capacidad para reaccionar no es solamente un asunto de las personas, es la punta extrema de una inteligencia colectiva y organizada (Dewey, 1927), inscrita en contextos materiales, que asocian humanos, equipamientos, objetos, saberes, reglas... Las movilizaciones colectivas no se juegan entonces en lo instantáneo de las transacciones que las componen: son siempre mediatizadas por complejos de símbolos y herramientas (Mead, 1934), que son tanto obligaciones como recursos, marcos como matrices, que relanzan a través de procesos de invención colectiva. Diversos ejemplos dan cuenta de la existencia de estos ensamblajes heteróclitos de humanos y de no humanos y del lugar de la intervención de mediadores y de traductores, operando en las interfaces entre instituciones, redes y organizaciones, relevando y recomponiendo las informaciones, denuncias o reivindicaciones. Lo más evidente es el lugar ocupado antes por el fax, hoy por internet o el teléfono, en los momentos fuertes de coordinación de estudiantes. El celular es el vector de la puesta en común entre las asambleas y los sindicatos de las diferentes universidades francesas, tanto en el plano de la difusión de las noticias en directo, como en el de la elaboración de una estrategia común y de la deliberación en relación a las propuestas que serán presentadas y las decisiones por tomar. De este modo, las modalidades de organización y de representación se han transformado: han emergido nuevas configuraciones de actores listos para hablar en nombre de... y para tomar posición en el espacio público. Del mismo modo, las movilizaciones de los trabajadores "sin-papeles" serían impensables sin los teléfonos celulares y las listas electrónicas que les permiten estar en contacto permanente, tenerse al tanto de las últimas informaciones, movilizarse rápidamente para responder frente a arrestos o para ocupar una empresa, y finalmente, 
coordinarse más allá de los temas locales, que los conciernen directamente o por filiales de interconocimiento, por la lengua o nacionalidad.

Pero no se trata aquí sólo de la herramienta técnica. El alcance de los medios de comunicación, como medios para colectar, elaborar y sintetizar informaciones, identificar, acercar y convencer colectivos, debatir, tomar decisiones y difundirlas bajo un modo viral, fue mucho más fuerte en el "mediactivismo" o el "ciberactivismo" que emergió en los años ochenta. Este toma diversas formas. Internet ofrece plataformas de coordinación, discusión y movilización para minorías activas u organizaciones militantes -redes ecologistas o antimilitaristas, asociaciones de defensa de los derechos del hombre o pacientes en el ámbito de la salud-. En respuesta al G7, los Open Economic Summits se organizaron desde 1984. En 1988, la Association for Progresist Communication federa un gran número de redes, mientras que la Conferencia Mundial de Mujeres de 1995 es un momento clave de la articulación de las luchas feministas a escala internacional. En Francia, la Red Asociativa y Sindical (R@S) se formó luego de las grandes manifestaciones de diciembre de ese mismo año. Cardon y Granjon (2010: 86) describen el "tejido de actores muy heterogéneos" que "va a ocupar la red de redes con el fin de comprometerse en las actividades del movimiento altermundialista". Los watchdogs, como los del Monde Diplomatique, vigilan los medios más vistos, critican las formas de hegemonía o de manipulación, denuncian la influencia de think tanks y de grupos de presión. Se pelean por la democratización del acceso a la información, contra su "mercantilización" o su "normalización", en todo caso contra la "desinformación" y por la transformación de los modos de regulación del espacio mediático. Los medios de comunicación alternativos, integrados en plataformas de información como Indymedia, mutualizan y "horizontalizan" sus recursos e informaciones. El periodismo ciudadano en línea, como Agoravox en Francia, la blogósfera y la twittósfera ya han penetrado en los espacios mediáticos, alterando el límite entre actividades profesionales y profanas. En Estados Unidos florecen las cadenas comunitarias, sostenidas por fundaciones, que difunden acciones políticas en las redes de internet y televisión. Luchan contra la comida chatarra o por la slow food, contra los efectos de los organismos genéticamente modificados en la agricultura, piden la erradicación de la deuda pública de los países del sur. Quieren que los flujos financieros paguen impuestos e instaurar así otra gobernanza mundial, boicotear a las empresas multinacionales sin ética, apoyar los movimientos de los sin-tierra a favor de la reforma agraria. Informan sobre los daños económicos, ecológicos y sociales del global business. Pero este uso de Internet lo encontramos también en otros lugares, hasta en países como China (Hua Linshan y Thireau, 2010).

Otras redes rompen con esta búsqueda de objetividad periodística, donde ven una nueva forma de "poder simbólico de élites militantes", y pretenden fundar colectividades autoorganizadas, que sobrepasan el corte entre producción y consumo: todo ciudadano debe convertirse en militante informacional, crear su blog, entregarse a experiencias de videoactivismo - llevando a cabo una ruptura con la prensa y el cine militantes, hasta entonces realizado por "expertos"-. La web participativa es el nuevo lema. En algunos casos, nuevas alianzas se forman entre activistas, periodistas, artistas, diseñadores, hacktivistas, como los defensores del software libre, que tienen una perspectiva cooperativista de control de 
los software y de las herramientas informáticas. De este modo, los lazos proliferan en las "comunidades virtuales", suscitando nuevas modalidades de compromiso de individuos y de articulación con otras formas de acción. La postura no es ya la de competir con los medios de comunicación oficiales (como los medios contrahegemónicos) o de luchas por la toma de poder (como la crítica social más clásica), sino hacer uso "táctico" de las nuevas tecnologías y crear nuevos modos de experiencia individual y colectiva. El espacio-tiempo numérico es supuestamente el lugar de prácticas de guerrilla (huelgas de Internet, bombardeos electrónicos, manifestaciones virtuales...), pero también de experimentaciones estéticas, innovaciones técnicas, invenciones identitarias. Sin duda, el software libre es actualmente un importante tema económico: algunos de sus miembros luchan utilizando el lobbying relativo a asuntos jurídicos de propiedad intelectual y de patentabilidad (open source, Creative Commons) y han declarado la guerra a Microsoft. Pero es también una red de desarrolladores, ante todo preocupados de este nuevo bien común, no mercantil, que es el software libre.

Esta consideración de los agenciamientos sociotécnicos es importante: son los lugares y motivos, marcos y recursos de movilizaciones colectivas. Estas ya no abren frentes de batalla como antes lo hacía el movimiento obrero. Pasan por dinámicas de contra-publicitación, que las metáforas de la hibridación y de la diseminación caracterizan mejor y que exigen nuevos formatos de compromiso. En este caso el compromiso se expresa en primera persona, con un tono libre y una parcialidad asumida, que se enfrenta a las reglas de funcionamiento de los antiguos espacios públicos. La cultura del happening, de la "mezcla" y de la "interferencia" (remix, jamming, slashing, sniping...) creó un nuevo estilo de activismo.

\section{LA INVENCIÓN DEL SENTIDO: DE LOS NUEVOS MOVIMIENTOS SOCIALES A LA CULTURAL SOCIOLOGY}

Todos estos trabajos sobre los agenciamientos sociotécnicos, las organizaciones y las redes integran poco a poco una dimensión cultural (Emirbayer y Goodwin, 1994; Jasper y Goodwin, 1999). Pero a menudo lo hacen como si fuera un parámetro como cualquier otro, un factor de causalidad que hay que tomar en cuenta para que el modelo de análisis sea más completo. Cuando la cuestión de la cultura se agregó a las hipótesis estructurales, racionales y mercantiles, con mayor intensidad al comienzo de los años ochenta, en Estados Unidos, fue bajo la forma de recursos estratégicos. La cultura entrega un "tool kit de hábitos, de capacidades y de estilos por medio de los cuales la gente elabora sus estrategias de acción" (Swidler, 1986: 273). Esta metáfora utilitarista tuvo gran éxito y podemos acercarla a la lectura que D. Snow hizo de los "marcos" de Goffman, como otro más de los "esquemas interpretativos" por medio de los cuales los actores definen situaciones, producen diagnósticos, proyectan pronósticos, enuncian críticas y también proveen justificaciones. La cuestión de la cultura es entonces planteada en términos de procesos de lineamiento de marcos, al interior de la organización y entre organizaciones: de conexión (bridging) entre públicos, de extensión (extension) hacia otras causas, de amplificación y de transformación, para que sean compatibles con marcos dominantes. Estos trabajos tuvieron su importancia e hicieron hincapié en la dimensión central de la presentación de sí y de la comunicación estratégica en la esfera pública (lo que Goffman Ilamaba impression management). Pero se han podido 
criticar porque este excedente cultural era finalmente metabolizado por la movilización de recursos, y porque las herramientas de análisis de estas configuraciones culturales eran más bien someras -poca recolección de datos in situ, análisis de contenido de "packagings", concepción causal del impacto sobre las acciones, poca consideración de la recepción de la parte de auditores (Cefaï, 2001)-.

En Europa, en paralelo, se desarrollaba una interrogación sobre los NMS, principalmente alrededor de A. Touraine y A. Melucci, pero también de C. Offe, K. Eder... Estos distintos investigadores comunicaban poco con "los Americanos" y en relación a los movimientos sociales, dos secciones de investigación cohabitaban en la Asociación Internacional de Sociología. En Europa, el acento estaba puesto sobre la temática de la "cultura" y de la "identidad". Simplificando, la idea inicial era que la clase obrera ya no era más el vector del movimiento social y del cambio histórico y que los NMS emergían a favor de nuevas contradicciones del capitalismo mundial y de una crisis de legitimidad del Estado (Offe, 1985), conducidos por franjas de clases medias y educadas más que por el proletariado campesino o urbano, para abrir nuevos espacios de conflicto. La serie de investigaciones del equipo de Touraine, que recurría al método de intervención sociológica (1978), analizó los "movimientos", tal como el estudiantil, antinuclear, feminista, regionalista, así como también el obrero (Touraine et al., 1984) sin olvidar un bello estudio sobre Solidarnosc en Polonia y diversos trabajos sobre Chile o Rusia. Melucci (1982) muy tempranamente se había interesado en lo que llamaba "áreas de movimientos", marcando un hito importante con la investigación colectiva de las movilizaciones de jóvenes (Centro Social Leoncavallo), mujeres (Donne del Ticinese), ecologistas (revista Nuova Ecologia) y espiritualistas (Centro Budista Ghe Pel Ling). En estos casos, constataba la transformación de los modos de compromiso: liderazgo difuso, organización reticular, fin de proyectos políticos globales, compromiso limitado en el espacio y el tiempo. Veía ahí sobre todo un desafío simbólico en los códigos morales y políticos y la invención de nuevas formas de vida, en un modo cada vez más trabajado por los procesos de racionalización y de normalización. Notemos que estas aproximaciones, sobre todo centradas en movimientos Ilamados "progresistas", ponían el acento en sitios de innovación y de experimentación, atentas a los fenómenos de emergencia de sentido, así como al carácter conflictivo de la movilización y las identidades colectivas que de ahí emergían. Pero tendían a veces a tomar atajos explicativos para llevar los NMS hacia transformaciones de la sociedad posindustrial, posmaterialista o posmoderna.

A fines de los años ochenta se constituye en Estados Unidos una cultural sociology, que permite pulir estas interrogaciones, perdiendo al mismo tiempo su germen normativo (Cefaï, 2007: parte 3). Las investigaciones tratan sobre los diferentes elementos que constituyen un colectivo. Sus miembros deben coordinarse, dedicarse a modalidades para estar juntos y trazar límites frente a otros colectivos -trabajar sobre el registro de los lazos (bonds) y las fronteras (boundaries)-. El proceso de identificación, de reconocimiento y de fábrica de un Sí compartido con otros -ya sea que se trate de revertir el estigma a través de movilizaciones homosexuales, de revitalizar una identidad étnica o bien de elaborar una identidad de género- es con frecuencia identificado como collective identity process (Melucci, 1996: 68-86). Es, a decir verdad, y en un sentido amplio, una dimensión de la 
constitución de experiencias públicas. Entrar en una movilización colectiva es elegir formas de sociabilidad y de solidaridad preferenciales; es delimitar las fronteras de inclusión y de exclusión en las concentraciones cívicas; es adentrarse en las relaciones de confianza, desde la confianza cercana en los affinity groups hasta la confianza ampliada, como en el caso de las "hermanas" en el movimiento de mujeres. Fantasia (1988) mostró, a propósito de la huelga de Clinton Corn, las implicancias de un repertorio de acción (Tilly, 1986) en términos de identidad y reciprocidad, de sociabilidad y solidaridad. Además del hecho de que la representación de la colectividad cambia para sus miembros o para sus espectadores, las fronteras de clase, de género y de raza, y las rutinas y los rituales de la vida cotidiana son alterados por la huelga. Las mujeres se convierten en bread-winners y los hombres en homekeepers, mientras que algunas desconfianzas en las relaciones interraciales desaparecen. Nuevos lazos de interconocimiento y de entreayuda se desarrollan en la ciudad: el sentido de la propiedad privada, la consciencia de clase y el amor por la nación son completamente alterados. La huelga, más allá del conflicto social, toca los mundos de la intimidad, de la casa, del trabajo y de la política. La cultural sociology se interesó también por los eventos de concentración -manifestaciones, conmemoraciones, meetings, fiestas, conciertos...concebidos para atraer público, mover los referentes de la experiencia colectiva, dar cuerpo a un movimiento celebrando su unidad, escandir la historia de su movilización a través de identificaciones memorables y recuadrar el activismo cercano, en lo cotidiano, a escalas espacio-temporales ampliadas. Creaciones originales o eventos rituales, las concentraciones tejen lazos y marcan fronteras, remodelan, de manera más o menos durable, horizontes de referencia territorial, de memoria y de proyecto de los participantes y espectadores. Pensemos en la fuerza de institución en el movimiento altermundialista de la contracumbre de la World Trade Organization en Seattle, en diciembre de 1999.

Esta reflexión en torno a los lazos y las fronteras va de la mano con una reflexión sobre las actividades rituales y simbólicas que permiten que el movimiento se mantenga unido y tenga visibilidad frente a los auditores. Una movilización colectiva debe ser puesta en forma, en escena y en sentido para existir. Abre arenas dramáticas, retóricas y narrativas donde nuevas realidades van a emerger (Cefaï, 2008). La investigación debe entonces restituir esta cualidad teatral de las movilizaciones colectivas: personajes endosan repertorios de roles en campos de acción, con sus justicieros, culpables y víctimas, sus problemas, sus alianzas y conflictos, objetivos, razones y valores. Participan de un drama público en el que son los coproductores, actores y espectadores. Y los escenarios cambian según si los actores se presentan ya sea en la escena mediática, judicial, política, administrativa, científica, militante, o bien simplemente en la escena de la vida cotidiana. La investigación debe igualmente examinar toda suerte de intrigas narrativas que se entretejen en una arena pública, y que atribuyen lugares de acción o de pasión. Puede tratarse del metarrelato de la lucha de clases que durante mucho tiempo guió las identidades colectivas, fijó el sentido de las luchas sociales y dibujó los horizontes históricos. Pero puede tratarse también, más allá de la estructura narrativa de las situaciones sociales, de historias contadas: la reanudación de la herencia del colonialismo, para interpretar las discriminaciones raciales o étnicas hoy en día, o la compilación de series estadísticas sobre el calentamiento climático, para resituar los desastres ecológicos del desarrollo capitalista, son el centro de movilizaciones colectivas. 
Pero puede también tratarse simplemente de historias de activistas (Johnston, 1991) que se transmiten entre ellos, en el contexto de reunión, que son enarboladas en las manifestaciones como testimonios dirigidos al público o que son contadas en libros que recopilan la memoria colectiva. Finalmente, la investigación debe seguir la producción, circulación y recepción de argumentos (Steinberg, 1999) por medio de los cuales los oradores más o menos autorizados toman posición, se dirigen a auditorios, se esfuerzan de persuadirlos y convencerlos, y así, eventualmente, van afinando sus armas retóricas -ya sean datos estadísticos, explicaciones causales, visiones interpretativas o razonamientos morales-. La retórica no debe ser aquí entendida como un arte de ilusión y de mentira. Un buen discurso logra poner en palabras una experiencia colectiva y le da una fuerza de publicitación sin igual a la causa -pensemos en I have a dream de Martin Luther King en la marcha de Washington del 28 de agosto de 1963-; que en general se traduce posteriormente en cadenas de acciones e interacciones que amplifican la movilización colectiva.

Lo interesante en todos estos enfoques, es que las movilizaciones colectivas instauran contextos de experiencia pública y privada, con sus diferentes dimensiones: sociabilidad, afectividad, sensibilidad, imaginario, memoria y proyecto. Son vectores de la invención democrática, que deshacen la ideología ambiente, y a través de estrategias de resistencia, de distanciamiento, de desafío o de reivindicación, abren espacios de posibles (Lefort, 1981). Crean frentes de conflictividad y lugares de participación, en torno a los que se recompone un mundo común y se diseminan focos de imaginación social e histórica (Castoriadis, 1974). Problematizan y publicitan situaciones que parecen ser evidentes y fijando la atención en los problemas públicos, pueden -con mayor o menor éxito...desplazar los referentes de experiencia individual y colectiva de actores, destinatarios o receptores. Las movilizaciones no sólo tienen impacto en las estructuras institucionales, legales o políticas. Sensibilizan a gente a formas de consumo, reorientan prejuicios o convicciones, invitan a votar, rezar, tomar o amar de otra manera, y a veces, invitan a participar en organizaciones militantes.

\section{MODOS DE COMPROMISO Y FORMAS DE EXPERIENCIA}

Los actores no actúan según un modo cívico todo el tiempo. Así como tampoco se comportan de manera permanente como buenos ciudadanos, su postura no es reductible a aquella de los buenos trabajadores, de los pequeños empresarios o pequeños soldados. En función del problema planteado, las fases de un conflicto o los momentos de una movilización, las personas se hacen ciudadanas, habitantes, consumidoras, creyentes, apoderados, víctimas de catástrofes, o incluso, defensores de una verdad histórica, de los derechos de una minoría, de la igualdad de géneros o de la justicia de clase -o quedan simplemente distanciados, por apatía o decepción, a veces, pero también por el rechazo a plegarse a una conminación de compromiso-. Las modalidades e intensidades de compromiso de los actores son de una gran variedad, que impiden ceñirlas sólo a modelos como el estructural, racional o estratégico. La gama de posibilidades de compromiso es más extensa que la alternativa entre exit, voice o royalty (Hirschman, 1970) y merece un trabajo profundo de observación, de escucha y de descripción. 
Primero podríamos identificar en la literatura disponible las diferentes maneras de oponerse, desde las más discretas hasta las más influyentes, desde las más íntimas a las más explícitas. En el espectro de las resistencias, están las prácticas infrapolíticas que buscan escapar al control social sin dar lugar a una lucha frontal: la pillería, la disimulación, el "arreglárselas", el humor, la ignorancia fingida, el hurto, la falta de apremio, el ausentismo y el doble juego de los discursos ocultos (hidden transcripts), desempeñados por sus pares y cómplices, en contrapunto a performances públicas destinadas a los más poderosos (Scott, 1990). Podemos igualmente describir las distintas actitudes frente a la cosa pública como diferentes grados de compromiso. La sensibilización hace que la atención de una persona se centre en un problema, pero este interés, a pesar de los peaks de indignación, no tiene la energía de la acción: el "ciudadano bien informado" permanece sentado frente a su televisión. La etapa siguiente es la participación episódica en concentraciones o manifestaciones: la adhesión del "simpatizante" lo conduce a dar de sí, a comulgar en las grandes ocasiones y a significar sus posicionamientos en público. Pero lo hace de manera efímera y episódica. El reclutamiento (McAdam, 1988) saca a las personas fuera de este claroscuro y los inserta de manera regular en medios y organizaciones, donde se espera de ellos actos y discursos que den cuenta de su compromiso. Los militantes de los partidos comunistas de otrora se dedicaban en cuerpo y alma a sus causas, estaban dispuestos a morir por el partido, adherían sin dudar a la ideología bolchevique o soviética al mismo tiempo que la reformulaban en variantes locales de comunismo municipal. Vivían en universos de sociabilidad y socialización que incluían, además del partido, a sindicatos y asociaciones, a escuelas y cooperativas, coros, centros de jóvenes y clubes deportivos... Hoy, tal nivel de fe es escaso. Pero la gestión organizacional requirió la formación de "profesionales del compromiso": algunos activistas hicieron de esto su profesión, fueron creados cursos y filiales de formación. Posteriormente, algunos fueron dirigentes y directores de grandes organizaciones no gubernamentales o estuvieron a la cabeza de federaciones de mutuales o de asociaciones. Otros, sin ser necesariamente asalariados, se convirtieron en nudos de redes y ocuparon posiciones claves de traducción y de difusión de informaciones, de coordinación entre diferentes universos de activismo, de conexión entre causas, de identificación de experimentaciones y de polinización de experiencias. Es una nueva combinación de saberes técnicos, de competencias profesionales y de capacidades activistas que se inventa.

Pero lo que parece haber retenido la atención de numerosos autores en relación a las metamorfosis del compromiso, son las nuevas "modalidades de subjetivación": "juegos de sí" de A. Melucci (playing Self), "política personal" de P. Lichterman (1996) o "compromiso liberado" de J. Ion (2001). La observancia de las grandes creencias parece abolida y habría dejado libre el campo a la multiplicidad de convicciones individuales. El lenguaje de la asociación voluntaria y de la desobediencia civil prevalece sobre el de la disciplina en la organización o de la pertenencia a una comunidad. La membership parece deber ser vivida como flotante y reversible, secante a una gran variedad de medios de interconocimiento, de redes de sociabilidad o de circuitos de comunicación. Constatamos una desafección de los aparatos institucionales, con su organización centralizada, jerarquizada y burocratizada, en beneficio de organizaciones horizontales, acéfalas o policéfalas, que favorecen un acceso directo a objetivos y acciones. Uno se compromete en función de una búsqueda personal, 
que puede tener la tesitura de la prueba iniciática, religiosa o terapéutica a la vez, rompiendo esta producción de sí con el militantismo total de antaño, pasando por un compromiso plural y discontinúo, sin marco ideológico, sin una intención totalizante. Incluso si se recompusiera hoy en día un metarrelato altermundialista, muchos activistas parecerían movidos por la urgencia humanitaria o ambiental o motivados por una convicción ética que los empuja a luchar por una causa dada. Los nuevos modos de creer no se acomodan a un dogma, católico o comunista. Y el sentido del deber, que iba a menudo con la abnegación de sí, cedió su lugar a una búsqueda de la realización de sí en la acción -aún para los radicales como los eco-warriors-. Antes, el compromiso se llevaba a cabo dejando mudo su sí, fundiéndose en los grandes colectivos y actuando en nombre de una necesidad objetiva. Hoy en día la experiencia íntima se expone en primera persona y a través de motivos como el sufrimiento o la humillación.

Estos análisis se hacen cargo de una mutación del militantismo, pero sobre todo no hay que sistematizarlos. La última palabra la tiene la investigación. Las representaciones de una individualización o, al contrario, de una comunitarización creciente del compromiso, deben ser puestas a prueba. El problema no es tanto de oponer compromiso personal o colectivo, sino de comprender cuáles son los momentos y las modalidades de la "personalización" y de la "colectivización" del compromiso. Gonzalez (2011) mostró que los modos de prueba de la presencia divina, vividos en primera persona por los evangélicos, deben ser comunicables en los "colectivos de experiencia" de las asambleas eclesiásticas, y que el rezo y el canto, al mismo tiempo que obran para la redención individual, pueden también hacerse políticos, cuando el pastor Ilama a los fieles a implorar la bendición del cantón de Ginebra. Esta experiencia colectiva no se elabora al azar. La gama de posibles en materia de asociación o de concentración está relacionada por aquello que Thévenot (2006) Ilamaría las "gramáticas de lo común". Más que considerar los colectivos como empresas mercantiles o comunidades étnicas, agrupaciones profesionales o partidos políticos, más que asignarles un principio único de existencia, basado en la clase o el género, la vecindad o el beneficio, y, en consecuencia, atribuir un tipo único de razones a los miembros, e identificar una lógica única respecto a sus intervenciones, hay que partir de una descripción compacta de sus experiencias de asociación y de reunión. Así, el sentido de estos modos de asociación aparece sólo gracias a una investigación etnográfica, que sigue las variaciones contextuales y las transformaciones temporales, a una investigación documental que trata sus materiales siguiendo la manera de los microhistoriadores o a una investigación biográfica no preformateada por un modelo de socialización. ¿En qué escena se comprometen, frente a qué auditorios, siguiendo qué objetivos, en relación a qué temas y en qué circunstancias?

Es sólo de esta manera que podemos comprender dos cosas. Primero, cómo los actores no están determinados por las condiciones estructurales, sino que tienen márgenes de maniobra en las situaciones y, sobre todo, ponen en jaque capacidades de actuar, individuales y colectivas, que pueden estar paralizadas o al contrario amplificadas y enriquecidas por la movilización -como lo mostraron los trabajos sobre los movimientos de pacientes afectados por el SIDA (Barbot, 2002) o miopatía (Callon y Rabeharisoa, 1999). La pregunta sobre los modos de compromiso y las formas de experiencia desemboca en la pregunta sobre las culturas 
cívicas, los agenciamientos sociotécnicos y las configuraciones de acción que favorecen o impiden dinámicas de empowerment. Segundo, esta investigación permite comprender cómo se hace la política. Esta no es sólo el fruto de deliberaciones o de decisiones tomadas colectivamente, en conciencia, por ciudadanos ejemplares, electos o expertos, sino que también se hace en contextos de experiencia en que domina la economía, la religión, la tecnología o la ecología. Se anida en las batallas de enfermos para obtener acceso a ciertas moléculas químicas, en las alertas lanzadas por asociaciones de ornitólogos a propósito de un pedazo de naturaleza, en proyectos experimentales de gestión de tratamiento de aguas urbanas o en asambleas de evangelistas donde la salvación le es prometida a los que rezaron por un candidato en las elecciones.

Ni ciudadano virtuoso, amante de la res publica, ni actor racional, preso de sus intereses privados: lo "personal" y lo "político" no son presupuestos de análisis que reenvían a una antropología utilitarista o republicana, sino que son modos de compromiso y formas de experiencia que se manifiestan en la movilización colectiva. Sólo una investigación cercana, que contornee los modelos disponibles en filosofía o en ciencia política, permite su comprensión.

\section{TRAYECTORIAS DE LOS INDIVIDUOS: UNIDADES O MULTIPLICIDADES DE ROLES Y PERSPECTIVAS}

Por supuesto, esta pregunta por las formas de experiencia puede igualmente ser abordada desde el punto de vista de su génesis. Un programa de investigación interesante, en francés, se centró en las trayectorias de compromiso, en torno a Fillieule (2001, 2005). Este se esforzó en descubrir las determinantes biográficas, principalmente de los activistas, las carreras de compromiso y de desvinculamiento. Reciclando el concepto de "carrera" de Hughes, Strauss o Becker, logró reintroducir un cierto azar y decisión en modelos demasiado estructuralistas o demasiado estratégicos. Fueron examinadas de cerca las sociabilidades y las temporalidades más o menos desajustadas de las "esferas de vida" militante, familiar y profesional, así como las incitaciones, impedimentos, reconversiones y desvinculamientos que éstas provocan (Passy, 2005). Pero por otra parte, el análisis biográfico quedó acoplado al análisis longitudinal de cohortes de compromiso. De esta manera, es posible retomar más claramente el despertar de "estructuras en desuso" (abeyance structures) de organización y movilización, y la reactivación de saberes y de contactos, de estrategias y de símbolos militantes, a veces después de décadas. El ejemplo clásico lo constituye el momento en que las sufragistas americanas que habían obtenido el voto en 1920 en el National Women Party pasan el relevo (por marginal que haya sido en los años cuarenta-cincuenta) a la National Organization for Women y al movimiento feminista de la mitad de los años sesenta (Taylor, 1989). Así se entienden mejor los desajustes y las tensiones que se producen en la cohabitación entre repertorios de acción y de experiencia de generaciones de activistas que se comprometieron en olas sucesivas y las distorsiones, las dificultades para comunicarse y para cooperar, y a veces los conflictos abiertos en el seno de ciertas organizaciones (Fillieule y Broqua, 2005). La consideración simultánea de las razones para actuar, de las cohortes generacionales, de las trayectorias personales (profesional, afectiva/sexual, en la enfermedad 
y en el activismo) y de las coyunturas de compromiso (campo de la solidaridad social en el Estado de bienestar, campo de las asociaciones de lucha contra el SIDA, perfil de la epidemiología del SIDA) permite comprender las "razones biográficas" de las "salidas de rol" y las "renegociaciones identitarias" de las personas que escogen el desvinculamiento.

Hemos visto que el ánalisis de redes permite tratar la cuestión de la multiposicionalidad, central para comprender la circulación de personas entre diferentes posiciones en redes sindicales y religiosas, por ejemplo, y las formas de cúmulo o de conversión de recursos o de capitales. Este análisis permite además mostrar los anclajes de una organización en redes familiares, tribales o profesionales, a veces territorializadas -lo que multiplica los criterios que deben ser considerados y afina el mapa de conexiones entre compromiso asociativo, sindical o político e inscripción en lazos de proximidad-. Esta multiposicionalidad es crucial: el espectro de los compromisos públicos de los activistas en múltiples compromisos es a menudo lo que permite el pluralismo de perspectivas en una organización, su apertura a ideas que vienen del exterior y su capacidad para innovar más allá de la simple reproducción. Pero también sucede que esta sea la fuente de "conflictos de roles" en un individuo, dividido entre distintos puntos de vista, modos de creer y maneras de hacer: debe cumplir un trabajo entre sus múltiples "personalidades sociales", ligadas a un entrecruzamiento de redes heterogéneas, para que ellas cohabiten en buen entendimiento, arreglándoselas a través de nuevas egosíntesis. Este procedimiento puede cruzarse con una prosopografía sistemática, que compile datos biográficos del conjunto de miembros de una organización. Ella puede servir a un análisis cuantitativo con el fin de identificar homologías entre propiedades sociales, modos de reclutamiento o estrategias de poder. Pero esta fue puesta a prueba en otra dirección por M. Gribaudi (1987). Practicando una microhistoria oral y documental de gran densidad y acomplándola con un análisis de redes egocentradas, tomado de la antropología de Manchester, Gribaudi nos transporta a los campos de experiencia concreta de los habitantes de un barrio de Turín, Borgo San Paolo, considerado bastión comunista durante mucho tiempo. Muestra que bajo las apariencias de una cultura obrera, convertida por lo demás en mito político en Italia, es posible distinguir una gran diversidad de aspiraciones y motivaciones, estrategias de interés y horizontes de expectativas ligadas a la movilidad geográfica y social de las personas y sus familias, modelos de identificación tomados de otros medios sociales... Igualmente, es posible reinterpretar los compromisos políticos en relación a los modos de inserción en redes de relación a escala microsocial, a las prácticas de vínculo, confianza y solidaridad entre vecinos, amigos y colegas, a las actividades rituales y simbólicas que celebran la identidad e igualdad entre obreros, con variaciones según la coyuntura política, en relación al advenimiento del fascismo y a dilemas morales causados por conflictos de lealtades... Este método permite comprender, más allá de los contornos prosográficos de un recorrido, las hesitaciones, los acomodamientos, las defecciones o las revueltas. Muestra que la política no se juega sólo en el orden de las opiniones y de los argumentos, de los razonamientos y las representaciones, pero que está atada a compromisos en la vida cotidiana. Permite aprehender cómo en este barrio de Turín la ideología socialista que parecía reinar sin división a principios del siglo XX se desintegra, correlativamente a la sociabilidad cercana que prevalecía y a la emergencia de estrategias individuales que se proyectan en nuevos espacios sociales y políticos -reestructurados por 
el fascismo emergente-. Entrega, más largamente, elementos de respuesta al por qué de las movilizaciones en favor del régimen fascista.

Estos análisis complejizan la comprensión que tenemos de trayectorias que podrían en un comienzo parecer erráticas. Y lo hacen sin romper con las perspectivas de los actores mismos, capaces de dar cuenta del sentido de lo que hacen y analizar sus incoherencias, giros, preferencias, tensiones y compromisos. Pero ni los efectos de cohorte ni las estrategias de interés explican todo. Los modos de asociación o de reunión en vista de defender un bien público o de alejar un mal público no tienen que ver sólo con una voluntad deliberada de individuos de movilizarse en conjunto, ni de la hipotética convergencia de sus emociones personales, ni de la búsqueda de beneficio en el sentido utilitarista del término, ni tampoco de métodos de recrutamiento por parte de empresarios. Hay que volver a interrogar las palabras comodín, como "sociabilidad", "sociabilidad", "socialización" y "asociación" para dar cuenta de cómo procesos de coordinación conducen a "construir lo común" y a "actuar en colectivo", y librarse a un trabajo de descripción, ya sea microhistórico, biográfico o etnográfico. ¿Cómo llegan las personas a vincularse y a obligarse unas a otras? ¿Mediante qué formas de apego se comprometen unas con otras, se tienen confianza mutuamente y se otorgan mutuo reconocimiento? ¿Cómo se coordinan sobre lo que hacen, pueden hacer y deben hacer? ¿Por qué vías sus experiencias concuerdan, se orientan hacia los mismos temas de denuncia o de reivindicación y comparten los mismos esquemas de comprensión y de acción? ¿Cómo, en una dinámica de publicitación, se sintonizan los cuerpos y se sincronizan, se coordinan en una experiencia común y se proyectan hacia finalidades compartidas? ¿Por qué caminos recomponen progresivamente experiencias que, sobrepasado el estadio de lo evidente, son comprendidas como malestares personales u obsesiones privadas? ¿Mediante qué interacciones entre ellos, nutridas por qué exploraciones de su entorno y mediadas por qué categorizaciones, descripciones, explicaciones y evaluaciones, logran reconocerse, a ponerle palabras a sus experiencias que les son comunes, a darse los medios para denunciar y reivindicar $y$, finalmente, crear colectivos que llevan su palabra frente a otros públicos potenciales?

Plantear estas preguntas es muy diferente a preguntarse cómo los líderes de los Social Movement Organizations (SMOs), sus agentes de comunicación, estrategas e ideólogos inventan consignas, eslóganes y argumentos con el fin de reclutar militantes, agregar adherentes y sumar simpatizantes. La cuestión es pertinente, y lo es más aún al encontrarnos en un espacio político que se parece a un mercado (o a un campo) donde productores atraen a consumidores recurriendo a una publicidad de tipo réclame comercial (o propaganda política). Pero pierde de vista todo lo que se juega detrás de la constitución de una experiencia pública, de una memoria colectiva o de un proyecto compartido. Confunde el mundo común con un mercado de bienes (o un campo de batalla).

\section{HACIA UNA INVESTIGACIÓN AMPLIADA EN LAS ARENAS PÚBLICAS}

¿Cómo una situación problemática engendra nuevas asociaciones, que no son simplemente aquellas que precedían en el mundo de la vida familiar, profesional, religiosa o política? 
¿Cómo se hacen y se deshacen estas asociaciones? ¿Qué las hace mantenerse juntas? ¿Y cómo logran, o no, proyectarse en un mundo común?

Las movilizaciones colectivas, ya sean movimientos sociales de envergadura internacional o acciones asociativas a escala local, remodelan los campos de experiencia y los horizontes de expectativas, privados y públicos, de los actores. Remodelan los ambientes cívicos y políticos, son fuente de innovaciones jurídicas e institucionales o, a la inversa, de procesos "contrademocráticos" que nutren un "populismo destructor" (Rosanvallon, 2006). Abren arenas públicas lanzando la carrera de nuevos problemas públicos y estimulando actividades de investigación, de experimentación y de deliberación -ya sean las de un periodista, sociólogo, practicante, juez, político o "ciudadano ordinario"-. Identificando problemas públicos, atribuyen relaciones de causalidad, califican faltas e imputan responsabilidades, instituyen órdenes de moralidad forjando estatutos de víctimas, de culpables y de jueces. Las movilizaciones participan de una dinámica de "invención democrática". Hacen emerger organizaciones, instauran nuevos frentes de alianza y de conflicto, fijan intereses y formulan derechos; recurriendo al testimonio, a la retórica o a la estadística, reorientan la atención de sus públicos, obran para convencerlos, sensibilizarlos y movilizarlos, y encuentran, o no, una transcripción en dispositivos de acción pública.

Este resultado es conforme a la herencia del pragmatismo. Dewey (1927) ponía en el origen de la definición de los problemas públicos los "procesos de asociación, de comunicación y de cooperación" en vistas de resolver una situación problemática. Las movilizaciones colectivas ganan al ser estudiadas en medio de procesos de emergencia, de objetivación, de legitimación, de institucionalización, y a veces de desaparición de problemas públicos. Hoy en día, un problema importante de investigación es seguir algunos dossiers y restituir el arco recorrido por las "políticas de la vida cotidiana", a ras de las costumbres, las emociones y las convicciones de las personas, hasta las tomas de decisión en las cimas del Estado -siguiendo la formación de problemas públicos a lo largo de batallas políticas, polémicas mediáticas, controversias tecnocientíficas, contiendas administrativas, procesos judiciales, disputas asociativas-. O inversamente, aprehender cómo los impulsos dados por movimientos sociales, pero también por empresas privadas o agencias de estado, hallan una traducción, a lo largo de cadenas de operaciones por ser definidas, hasta las experiencias vividas de las personas. En resumen, reconstruir arenas públicas, con sus escenas, sus "trasescenas" ${ }^{6}$, sus repertorios y sus auditorios, y los procesos de definición y de resolución de problemas públicos que tienen lugar ahí.

Entre los temas de investigación que se desarrollan hoy, uno de los más interesantes tiene lugar en la frontera de la sociología de las movilizaciones colectivas, de la acción pública y de los problemas públicos. Los problemas públicos son a menudo estudiados siguiendo un programa. Aparecen como el producto de un arbitraje entre decisiones políticas, procesos tecnocráticos, preferencias ideológicas, arquitecturas cognitivas, cálculos electorales, rutinas administrativas, costos institucionales, recursos presupuestarios, campañas mediáticas y

6 N. del T.: Remite al término que desarrollara Goffman de backstage, es decir, la idea de "tras bambalinas". 
movilizaciones colectivas (Baumgartner y Mahoney, 2005). Algunos han tenido una lectura ecológica de sus éxitos o de sus fracasos: los problemas logran abrirse camino en una competición con otros problemas para acceder al espacio mediático, administrativo y político: la atención es un recurso escaso cuya captación es foco de lucha entre organizaciones que apoyan una u otra causa. Otros han estudiado de cerca los círculos exclusivos donde, al margen de la escena pública, políticos electos, altos funcionarios, lobbistas de grupos de presión o representantes de partidos, sindicatos y asociaciones, entran en relaciones de poder, de influencia y de presión -hasta la toma de decisiones por parte del ejecutivo, el voto de leyes por parte del legislativo o la aplicación de medidas por parte de la administración (para un panorama: Hassenteufel, 2008; Lascoumes y Le Galès, 2007)-. Cada vez más cientistas políticos analizan el "nexus movimiento social-político público": muestran cómo emerge un ámbito de acción pública, con sus profesionales, sus agencias y sus organizaciones, que entablan una relación de colaboración con los representantes del Estado, e inversamente, cómo las políticas públicas que han sido puestas en marcha, reorganizan el espacio de reivindicaciones y reordenan sus propios objetivos (Burstein, 1999). Los diferentes niveles y las diferentes etapas del policy-making process -la creación de un problema, la adopción de una solución en un espacio de alternativas, la elaboración de normas por parte de los poderes instituidos y la aplicación de normas por parte de agentes en las circunstancias reales de la definición primera de un problema- se apoyan sobre diferentes configuraciones de movilización colectiva.

Si tomamos por ejemplo la cuestión ecológica, el problema para las ciencias sociales no será solamente el investigar sobre organizaciones ambientalistas, sino que sobre los múltiples lugares y momentos en que el medio ambiente se transforma en cosa pública (Latour y Weibel, 2005). Todo tipo de experiencias y de actividades tiene que ver con la movilización colectiva en torno a un problema público. Esta enrola asociaciones que colectan testimonios y elaboran argumentos, investigadores que producen estadísticas y modelos, juristas que imaginan nuevas nociones de derecho, practicantes que experimentan objetos inéditos en vista de su difusión comercial, instituciones estatales que distribuyen sus recursos, movilizan sus servicios de investigación, financian laboratorios de investigación, activan redes de acción pública. Según el caso, será interesante investigar sobre la manera en que algunos laboratorios de investigación producen nuevos saberes experimentales en energía solar o modelos predictivos en química experimental, a partir de los cuales hacer emerger nuevos dispositivos técnicos de medición de la contaminación o de fabricación de electricidad. Podremos dejar el espacio de los movimientos sociales para examinar cómo las empresas privadas transforman el universo de los objetos técnicos, de medios de transporte y de bienes de consumo que nos rodean, desarrollan nuevas filiales de agricultura biológica o de equipamiento energético, crean nichos en mercados reservados o abiertos y suscitan nuevas formas de consumo - provocando nuevos procesos de movilización, individual o colectiva-. Podremos igualmente ver cómo las agencias públicas responden a los objetivos estratégicos (institucionales, parlamentarios, políticos, reglamentarios...) de los "movimientos ecológicos", con una tasa de logro más o menos elevada -cómo las denuncias sobre la peligrosidad de las moléculas químicas se traducen en reglamentaciones a nivel europeo y cómo investigaciones públicas son aplicadas, apoyadas en experimentaciones de control-. 
Examinaremos cómo los activistas defienden su entorno inmediato frente a la transformación de las costumbres de consumo o militan en asociaciones de defensa de la naturaleza, con la única vocación de preservar o informar, o cómo se federan y se alían en partidos que entran en el juego electoral de la democracia representativa. O también, cómo contribuyen a remodelar los dispositivos de participación y de deliberación, proponiendo por ejemplo jurados ciudadanos o conferencias de consenso... Hasta otorgarle derechos a las plantas y a los animales y, en especulaciones visionarias, imaginar crear un "parlamento de los objetos" (Latour, 1999). Y mostraremos cómo estas redes insólitas son distintos medios de incubación y vectores de difusión de nuevas afectividades, sensibilidades y moralidades, enraizadas en experiencias corporales y espirituales ; y cómo transforman las pruebas que los públicos tienen de sus ambientes vividos, "naturales" o "artificiales" compartiéndolas con otras personas, próximas o lejanas (Lolive, 2006). Y cómo crean, para el público, nuevas ideas trascendentes, como la defensa de la biodiversidad, el principio de precaución, el patrimonio de la humanidad, el amor de la Madre-Tierra (Micoud, 2007)... Nuevos principios éticos, políticos o metafísicos -que han podido ser calificados como "cosmopolíticos"-.

La sociología de las movilizaciones colectivas no se limita a estudiar la formación de "movimientos sociales". Rastrea más bien la multiplicidad de acciones de individuos, de organizaciones y de instituciones que buscan definir, regular o resolver tal o cual problema público, reconocido por su interés general. Esta ampliación de la investigación hacia arenas públicas implica interrogarse sobre los esfuerzos de los humanos para hallar modus vivendi y para el buen vivir juntos y sobre sus capacidades para inventar formas de "democracia creativa" (Dewey). La sociología de las movilizaciones colectivas debe hacer suya esta preocupación política.

\section{BIBLIOGRAFÍA}

Barbot, J. (2002): Les malades en mouvements. La médecine et la science à l'épreuve du sida, Balland, Paris.

Baumgartner, F. y C. Mahoney (2005): "Social Movements, The Rise of New Issues, and the Public Agenda", en D.S. Meyer, V. Jenness y H. Ingram (eds.): Routing the Opposition: Social Movements, Public Policy, and Democracy, University of Minnesota Press, Minneapolis, pp. 65-86.

Boltanski, L. y L. Thévenot (1991): De la justification. Les économies de la grandeur, Gallimard, Paris. Bourdieu, P. (1979): La distinction, Minuit, Paris.

(1980): Le sens pratique, Minuit, Paris.

Breviglieri, M. y L. Pattaroni (2005): "Le souci de propriété. Vie privée et déclin du militantisme dans un squat genevois", en B. Haumont y C. Morel (dir.): La société des voisins, Éditions de la MSH, Paris, pp. 275-289.

Burstein, P. (1999): "Social Movements and Public Policy", en M. Giugni, D. McAdam y C. Tilly (eds.): How Social Movements Matter, University of Minnesota Press, Minneapolis, pp. 3-21.

Callon, M., P. Lascoumes e Y. Barthe (2001): Agir dans un monde incertain. Essais sur la démocratie technique, Seuil, Paris. 
Callon, M. y V. Rabeharisoa (1999): Le pouvoir des malades. L'Association française contre les myopathies et la recherche, Presses de l'École des Mines, Paris.

Cardon, D. y F. Granjon (2010): Médiactivistes, Presses de Sciences Po, Paris.

Castoriadis, C. (1974): L'Institution imaginaire de la société, Seuil, Paris.

Cefaï, D. (2007): Pourquoi se mobilise-t-on? Théories de l'action collective, La Découverte, Paris.

(2008): "Boire ou conduire, il faut choisir! La fabrique des problèmes publics", epílogo a J. Gusfield: La culture des problèmes publics, Economica, Paris, pp. 219-318.

Cefaï, D. y D. Trom (eds.) (2001): Les formes de l'action collective. Mobilisations dans des arènes publiques, Éditions de l'EHESS, Paris (colección "Raisons pratiques", vol. 12).

Chateauraynaud, F. y D. Torny (1999): Les sombres précurseurs. Une sociologie pragmatique de l'alerte et $d u$ risque, Éditions de l'EHESS, Paris.

Dewey, J. (1927): The Public and its Problems, Henry Holt, New York.

Diani, M. (1992): "The Concept of Social Movement", The Sociological Review, 40, pp. 1-25.

Diani, M. y D. McAdam (dir.) (2003): Social Movements and Networks, Oxford University Press, Oxford.

Dodier, N. (2003): Leçons politiques de l'épidémie de sida, Éditions de l'EHESS, Paris.

Eliasoph, N. (2011): Making Volunteers: Civic Life After Welfare's End, Princeton University Press, Princeton.

Emirbayer, M. y J. Goodwin (1994): "Network Analysis, Culture, and the Problem of Agency", American Journal of Sociology, 99, pp. 1411-1454.

Fantasia, R. (1988): Cultures of Solidarity: Consciousness, Action, and Contemporary American Workers, University of California Press, Berkeley.

Fillieule, O. (2001): “Post-scriptum: Propositions pour une analyse processuelle de l'engagement individuel", Revue Française de Science Politique, 51 (1-2), pp. 199-217.

(2005): "Temps biographique, temps social et variabilité des rétributions", en O. Fillieule (dir.): Le désengagement militant, Belin, Paris, pp. 17-47.

Fillieule, O. y C. Broqua (2005): "La défection dans deux associations de lutte contre le sida: Act Up et AIDES", en O. Fillieule (dir.): Le désengagement militant, Belin, Paris, pp. 189-228.

Giugni, M. (1998): "Social Movements and Change: Incorporation, Transformation, and Democratization", en M. Giugni, D. McAdam y C. Tilly (eds.): From Contention to Democracy, Rowman \& Littlefield, Lanham, pp. xi-xxvi.

Gonzalez, P. (2011): "Revendiquer la nation suisse au nom de Dieu. Lorsque la prophétie se fait politique dans une église évangélique", en D. Cefaï, M. Berger y C. Gayet (eds.): Du civil au politique. Ethnographies du vivre-ensemble, Peter Lang, Bruxelles, pp. 167-204.

Gribaudi, M. (1987): Itinéraires ouvriers. Espaces et groupes sociaux à Turin au début du XXe siècle, Éditions de l'EHESS, Paris.

Hassenteufel, P. (2008): Sociologie politique: I'action publique, Colin, Paris.

Hirschman, A. (1970): Exit, Voice, and Loyalty, Harvard University Press, Cambridge.

Hua Linshan e I. Thireau (2010): Les ruses de la démocratie, Seuil, Paris.

Ion, J. (2001): "Affranchissements et engagements personnels", en J. Ion: L'Engagement au pluriel, Presses de l'Université de Saint-Étienne, Saint-Étienne. 
Israël, L. (2009): L'Arme du droit, Presses de Sciences Po, Paris.

Jasper, J. (1992): "The Politics of Abstractions: Instrumental and Moralist Rhetorics in Public Debate", Social Research, 59 (2), pp. 315-344.

(1997): The Art of Moral Protest: Culture, Biography, and Creativity in Social Movements, University of Chicago Press, Chicago.

Jasper, J. y J. Goodwin (1999): "Caught in a Winding, Snarling Wine: The Structural Bias of Political Process Theory", Sociological Forum, 14 (1), pp. 27-54.

Johnston, H. (1991): Tales of Nationalism: Catalonia 1939-1979, Rutgers University, New Brunswick.

Kaufmann, L. y D. Trom (2010): Qu'est-ce qu'un collectif? Du commun à la politique, Editions de I'EHESS, Paris (colección "Raisons pratiques", vol. 20).

Knoke, D. (1990): Political Networks: The Structural Perspective, Cambridge University Press, Cambridge.

Koselleck, R. (1997): L'Expérience de l'histoire, Gallimard-Seuil, Paris.

Ladrière, P., P. Pharo y L. Quéré (dir.) (1993): La théorie de l'action, Éditions du CNRS, Paris.

Laraña, E., H. Johnston y J. Gusfield (1994): New Social Movements: From Ideology to Identity, Temple University Press, Philadelphia.

Lascoumes, P. y P. Le Galès (2007): Sociologie de l'action publique, Colin, Paris.

Latour, B. (1999): Politiques de la nature. Comment faire entrer les sciences en démocratie, La Découverte, Paris.

Latour, B. y P. Weibel (eds.) (2005): Making Things Public: Atmospheres of Democracy, MIT Press, Cambridge.

Lefort, C. (1981): L'Invention démocratique, Fayard, Paris.

Leonardis, O. de (1990): Il terzo escluso. Le istituzioni come vincoli e come risorse, Feltrinelli, Milan.

Lichterman, P. (1996): The Search for Political Community: American Activists Reinventing Commitment, Cambridge University Press, New York.

Lolive, J. (1999): Les contestations du TGV Méditerranée, L’Harmattan, Paris.

(2006): "Des forums hybrides à l'esthétisation des espaces publics", Cahiers de géographie du Québec, 50 (140), pp. 151-171.

Matonti, F. y F. Poupeau (2004): "Le capital militant: essai de définition", Actes de la Recherche en Sciences Sociales, 155 (5), pp. 4-11.

McAdam, D. (1988): "Micromobilization Contexts and Recruitment to Activism", International Social Movement Research, 1, pp. 125-154.

(1988): Freedom Summer, Oxford University Press, New York.

McAdam, D., S. Tarrow y C. Tilly (2003): Dynamics of Contention, Cambridge University Press, Cambridge.

Mead, G.H. (1934): Mind, Self, and Society, University of Chicago Press, Chicago.

Melucci, A. (1982): L'Invenzione del presente. Movimenti, identità, bisogni individuali, Il Mulino, Bologna.

(1996): Challenging Codes, Cambridge University Press, Cambridge.

Micoud, A. (2007): "De l'expert-militant à l'être vivant sensible", en "Esthétique et espace public", Cosmopolitiques, 15, pp. 121-134. 
Micoud, A. y M. Peroni (eds.) (2000): Ce qui nous relie, Éditions de l'Aube, La Tour d'Aigues.

Mische, A. (2008): Partisan Publics: Communication and Contention Across Brazilian Youth Activist Networks, Princeton University Press, Princeton.

Mouchard, D. (2009): Être représenté. Mobilisations d'«exclus» dans la France des années 1990, Economica, Paris.

Oberschall, A. (1973): Social Conflict and Social Movements, Prentice Hall, New Jersey, Englewood Cliffs.

Offe, C. (1985): "New Social Movements: Changing Boundaries of the Political”, Social Research, 52, pp. 817-868.

Osa, M. (2001): Solidarity and Contention: The Networks of Polish Opposition 1954-81, University of Minnesota Press, Minneapolis.

Passerini, L. (1988): Autobiografia di gruppo, Giunti, Florence.

Passy, F. (2005): "Interactions sociales et imbrications des sphères de vie", en O. Fillieule (dir.): Le désengagement militant, Belin, Paris, pp. 111-130.

Peroni, M. y J. Ion (eds.) (1997): Engagements publics et exposition de la personne, Éditions de l'Aube, La Tour d'Aigues.

Peroni, M. y J. Roux (eds.) (2006): Sensibiliser. La sociologie dans le vif du monde, Éditions de l'Aube, La Tour d'Aigues.

Pizzorno, A. (1986): "Some Other Kind of Otherness: A Critique of Rational Choice Theories", en A. Foxley, M. McPherson, G. O'Donnell (eds.): Development, Democracy, and the Art of Trespassing: Essays in Honor of Albert O. Hirschman, University of Notre Dame Press, Notre Dame, pp. 355-373.

Quéré, L. (2002): "La structure de l'expérience publique d'un point de vue pragmatiste", en D. Cefaï e I. Joseph (dir.): L'Héritage du pragmatisme. Conflits d'urbanité et épreuves de civisme, Éditions de l'Aube, La Tour d'Aigues, pp. 131-160.

Rosanvallon, P. (2006): La contre-démocratie. La politique à l'âge de la défiance, Seuil, Paris.

Sarat, A. y S.A. Scheingold (2006): Cause Lawyers and Social Movements, Stanford University Press, Stanford.

Sawicki, F. (1997): Les réseaux du Parti socialiste. Sociologie d'un milieu partisan, Belin, Paris.

Schütz, A. (1962-66): Collected Papers, Martinus Nijhoff, La Haye.

Scott, J.C. (1990): Domination and the Arts of Resistance: Hidden Transcripts, Yale University Press, New Haven.

Steinberg, M. (1999): "The Talk and Back Talk of Collective Action: A Dialogic Analysis of Repertoires of Discourse Among Nineteenth Century English Cotton Spinners", American Journal of Sociology, 105, pp. 736-780.

Swidler, A. (1986): "Culture in Action: Symbols and Strategies", American Sociological Review, 51 (2), pp. 273-286.

Tarrow, S. y C. Tilly (2007): Contentious Politics, Paradigm Pub, London/Boulder.

Taylor, V. (1989): "Social Movement Continuity: The Women's Movement in Abeyance", American Sociological Review, 54 (5), pp. 761-775. 
Thévenot, L. (2006): L'Action au pluriel. Sociologie des régimes d'engagement, La Découverte, Paris.

Thompson, E.P. (1971): "The Moral Economy of the English Crowd in the 18th Century", Past \& Present, 50, pp. 76-136.

Tilly, C. (1978): From Mobilization To Revolution, Addison-Wesley, Reading. (1986): La France conteste de 1600 à nos jours, Fayard, Paris.

Touraine, A. (1978): La voix et le regard, Seuil, Paris.

Touraine, A., F. Dubet y M. Wieviorka (1984): Le mouvement ouvrier, Fayard, Paris.

Trom, D. (1999): “De la réfutation de l'effet Nimby considérée comme une pratique militante. Notes pour une approche pragmatique de l'activité revendicative", Revue Française de Science Politique, 1, pp. 31-50.

Zald, M. y J. McCarthy (1977): "Resource Mobilization and Social Movements: A Partial Theory", American Journal of Sociology, 82, pp. 1212-1241.

Recibido: 04-10-2010

Aceptado: 05-04-2011 